\title{
El patrimonio del César ante el Perro Guardián: un análisis de Periodismo de Precisión sobre la transparencia económica de los miembros del Gobierno en España
}

\author{
Laura TEJEDOR FuENTES \\ Universidad Complutense de Madrid \\ ltejedorfuentes@gmail.com \\ José Luis DADER GARCÍA \\ Universidad Complutense de Madrid \\ dader@ccinf.ucm.es
}

Recibido: 15/03/2011

Aceptado: 19/09/2011

\begin{abstract}
Resumen
La información administrativa sobre la actividad de altos cargos y funcionarios continúa en España bajo importantes restricciones en cuanto pueda afectar a datos personales de cualquier índole, conforme a la prevalente protección en nuestro país de la privacidad sobre el derecho a la información de interés público. Aun así, desde el año 2009 se ha producido alguna apertura reglamentaria en materia de declaración de patrimonio e intereses socioeconómicos de miembros del Gobierno y diputados, lo que constituye un tímido avance hacia la transparencia democrática de la documentación administrativa de interés general. Mediante el acceso a las correspondientes bases de datos, el periodismo de precisión como especialidad dedicada al cruce o contraste sistemático de grandes conjuntos de datos objetivados sobre asuntos de interés público, obtiene así una oportunidad de contribuir a la transparencia democrática en cuestiones que pudieran afectar al desvelamiento de irregularidades, desequilibrios institucionales o simple conocimiento ciudadano de los datos contrastados de la actividad de los servidores públicos. A través de una petición concreta de datos y de acceso a los correspondientes ficheros de reciente liberación, este artículo muestra los resultados de una aplicación del periodismo de precisión al conocimiento de la situación económica e intereses de los principales miembros del poder Ejecutivo, al tiempo que pone de manifiesto la debilidad e insuficiencia de alcance que las citadas modificaciones legales suponen aún para una fiscalización plena de la responsabilidad de los representantes políticos.
\end{abstract}

Palabras clave: Información pública, acceso a información administrativa, transparencia democrática, periodismo de precisión, investigación periodística.

\section{The Caesar's Wealth before the Watchdog: A Precision Journalism analysis about financial transparency of Government Cabinet in Spain}

\begin{abstract}
The administrative information about top officials and civil servants' activities in Spain is still kept under important restrictions. Such limitation is particularly severe on personal data of any type related to these politicians, in accordance with the Spanish preference for protection to privacy over the right to public interest information. Even so, since 2009 some regulations openness has taken place in relation to Government and Parliament members' declarations about their assets, their personal economic interests and their business ties. The new regulation supposes a tiny advance towards a democratic transparency of general interest administrative documentation. Through the access to the specific data bases, precision jour-
\end{abstract}

${ }^{1}$ Este artículo se basa en una parte de la investigación presentada como Trabajo Fin de Master en el Máster Oficial de Periodismo de la UCM, en junio de 2010. El material empleado ha sido específicamente ampliado y actualizado para esta edición. 
nalism -a newsmedia strategy specialized on computer cross-checking and matching of big data collections-, contributes to a real democratic transparency by means of the disclosure of unveil irregularities, institutional unbalances or just basic data about public servants' activities which can improve the control of the public institutions responsiveness by the citizens. Across an accurate data petition and the access to the specific datafiles recently unlocked to the public scrutiny in Spain, this article shows the results of an application of precision journalism to the case of the main directors of the executive power regarding their personal assets, complementary incomes and business connections. Nevertheless, the poor data specification showed in the disclosure records of the Spanish Administration seriously restricts the goal of a full watchdogging of the political representatives.

Keywords: public information, access to administrative information, democratic transparency, precision journalism, journalistic investigation, database matching.

\section{Referencia normalizada}

TEJEDOR FUENTES, Laura y DADER GARCÍA, José Luis (2011): “El patrimonio del César ante el Perro Guardián: Un análisis de Periodismo de Precisión sobre la transparencia económica de los miembros del Gobierno en España”. Estudios sobre el mensaje periodístico. Vol. 17, núm. 2, págs.: 431-455. Madrid, Servicio de Publicaciones de la Universidad Complutense.

Sumario: 1. Introducción. 2. El periodismo de precisión, una herramienta de indagación sistemática de bases de datos. 3. La transparencia informativa vs. el terror panóptico. 4. El proteccionismo de los datos públicos en España. 5. Las "Freedom of information Acts". 6. La poca claridad y transparencia de nuestra legislación. 7. La apertura legislativa ¿El inicio del cambio?. 8. Un ejercicio de periodismo de precisión sobre las declaraciones patrimoniales del Gobierno. 9. La correlación entre variables: El gráfico de dispersión y la recta de regresión lineal sobre los datos analizados. 10. La distancia a la quiebra de los cargos públicos. 11. Un avance con lagunas. 12. La tímida reacción de los medios. 13. Referencias bibliográficas.

"El poder genuino es esencialmente inescrutable. Quienes están sujetos a él ignoran hasta su misma existencia". (Pablo Salvador Coderch, 2010)

\section{Introducción}

La situación existente en España de evidente falta de acceso a datos públicos, fruto de un legado histórico secretista, ha generado y genera importantes debates entre juristas, académicos y especialistas de diversas áreas. Los avances han sido mínimos en un país donde, a pesar de que la Constitución defiende el derecho a la información, no existe una ley específica de derecho de acceso a la información, cuando menos en lo referente a la documentación obrante en los archivos de la Administración Pública.

Uno de los más significativos y escasos avances en este campo tuvo lugar en 2009, con la aprobación de las nuevas reglamentaciones sobre acceso a datos personales de cargos institucionales, que modificaron parcialmente el contexto jurídico y mediático del acceso a datos en nuestro país.

Este artículo pretende analizar las consecuencias de esta modificación mediante la utilización del periodismo de precisión, una modalidad basada en la aplicación de procedimientos sistematizados y altamente formalizados de comparación, agrupación y relación estadística de datos que permite elaborar una información periodística relevante. Implica, además, un proceso de indagaciones por iniciativa de los profesionales, que tiene como fin profundizar en la investigación periodística de unas bases de datos. 
La hipótesis general que pretende analizar este estudio es si las recientes medidas adoptadas por el Gobierno de España sobre acceso público a datos de patrimonio de Gobierno y Altos cargos suponen un avance en la transparencia en materia de ficheros públicos de nuestro sistema democrático. Por otro lado, procura responder a dos preguntas de investigación: ¿Qué cambios específicos introduce la promulgación de estas leyes y reglamentos en la democracia española? y ¿En qué medida la incorporación al acceso público de estas declaraciones puede contribuir al aumento de ejercicio del 'periodismo de precisión' en España?

\section{El periodismo de precisión, una herramienta de indagación sistemática de bases de datos}

El periodismo de precisión es un tipo de periodismo que surge como reacción al convencional, por medio del acercamiento a la sociología, la estadística y el rastreo de datos informatizados.

La llamada precisión consiste en la aplicación de procedimientos sistematizados y altamente formalizados (mayoritariamente cuantitativos) a conjuntos de datos cuyas relaciones pueden hacer aflorar una información periodística relevante que permanecería inadvertida en caso de un tratamiento coyuntural de datos aislados. Implica un proceso de indagaciones (basado en la iniciativa de los profesionales), a diferencia del llamado periodismo de declaraciones, en el que el periodista se limita a organizar, sintetizar o relacionar las revelaciones de una o varias fuentes. Desde el punto de vista de los beneficios de un periodismo de investigación supone incluso un avance de rendimiento informativo al constituir el paso del modelo tipo 'wikileaks', en el que unos profesionales cuentan de manera impresionista unos datos revelados por una fuente, a la investigación por iniciativa de los periodistas de unas bases de datos a las que se les aplican criterios sistematizados de comparación, agrupación, cuantificación, relación estadística, etc..

En términos más estrictos podemos recurrir a la definición que califica esta modalidad profesional de "información periodística que elabora o analiza con rigor científico-técnico datos numéricos o empíricamente verificados mediante métodos de investigación psicosocial, estadística o de tratamiento informático sobre cualquier asunto de trascendencia social y relevancia pública" (DADER, 2009).

Philip Meyer, el autor que acuñó el término e inició la delimitación académica y práctica de la especialidad, aporta una definición aún más sintética: "Aplicación de métodos científicos de investigación social y comportamental a la práctica del periodismo" (Meyer, 1989: 196).

El desarrollo del enfoque de la precisión requiere que los profesionales del periodismo se formen en áreas más técnicas que las del periodista convencional, incluyendo conocimientos de estadística, sociología e informática. Junto a esto, este profesional debe aspirar a un cambio de perspectiva que le permita indagar las noticias más allá de la casualidad o apariencia sorpresiva del hecho aislado. Su objetivo consistirá así en medir la estructura global de los fenómenos (para establecer tendencias dominantes), realizar cuantificaciones verificables de evidencias formales sobre personas o hechos, incorporar al periodismo no sólo técnicas cuantitativas sino tam- 
bién cualitativas de investigación científica empírica y centrar su interés en la consistencia de los métodos empleados en su tratamiento de los datos -mediante la constante comprobación del procedimiento seguido-, antes que en la mayor espectacularidad o no de los propios resultados. Todo esto, basado en la objetividad de los datos, que dependerá a su vez de la transparencia de los métodos.

\section{La transparencia informativa vs. el terror panóptico}

La transparencia informativa de datos sobre la realidad social constituye un pilar de la democracia, ya que no puede darse una democracia sin que los ciudadanos tengan un acceso libre a cuanta información obrante en manos de los representantes pueda afectar al ejercicio de sus derechos. Este mismo motivo constituye la base del trabajo de investigación del periodismo en general, tal y como de forma también genérica establece la tradición de su función de perro guardián de las instituciones y los actores políticos, y que mediante procedimientos más específicos pretende depurar y potenciar el periodismo de precisión.

Pese a todo, el ser humano ha tardado en comprender la importancia de dichos valores en el desarrollo de la sociedad y los primeros referentes de publicidad de los asuntos estatales tienen fecha reciente. El primer avance significativo surge en el siglo XVIII, cuando el ministro ilustrado de finanzas de Luis XVI, Jaques Necker, abrió a conocimiento público los ingresos y gastos del Estado al considerar que la buena opinión del pueblo respecto a su actividad política dependía de una gran claridad en la rendición de cuentas (SPEIER, 1972:103).

Este afán democrático dio lugar a un impulso que seguiría evolucionando hasta llegar al siglo XIX, cuando se concibe y organiza una democracia, no sólo ideal, sino constitucionalmente operativa, basaba en la soberanía popular y en su configuración cotidiana del tribunal de la opinión pública. Jeremy Bentham fue uno de sus impulsores, pues creía que el control y la inspección de los poderes públicos por parte de los ciudadanos es la mejor garantía de democracia.

Sin embargo, el paso de los años y la complejidad de la colisión entre derechos individuales y colectivos ha debilitado la identificación radical entre transparencia pública y democracia que alentó a los liberales del XIX, dando lugar a lo que José Luis DADER (2001: 151) denomina "el terror panóptico". Este autor menciona la popular novela de 1984 de George Orwell, como el emblema en el que muchos autores como Michael Foucault basan sus alegatos contra una amplia transparencia al considerarla instrumento de un control informativo unidireccional por el Estado. A partir de esa percepción, dicha línea de pensamiento desemboca en la exigencia de ocultación de datos a la mirada pública, en apelación también a principios democráticos.

Por éste y otros factores, la posibilidad de efectuar un control social por medio de cualquier procedimiento de observación ha venido siendo identificada por una corriente intelectual y legislativa autoconsiderada progresista como una intromisión totalitaria, que dejaría la reputación o la buena imagen de los individuos desprotegida ante la contemplación indiscriminada de los demás. No es el momento de entrar a analizar cómo tal perspectiva sólo puede provenir de una miope confusión de lo público con lo privado. Bastará señalar, sin embargo, que es precisamente la puesta en 
público de los asuntos que afectan al conjunto de la comunidad lo que permite que las personas gocen de más conocimiento y por tanto, de más libertad. En esta línea, organizaciones pro transparencia insisten en el cese de la ocultación de los asuntos administrativos, fiscales y de gestión de los políticos, ya que la opacidad de todo ello suele tener costes que se traducen en una mayor corrupción.

Entre las organizaciones nacionales orientadas en esta última dirección se encuentra la Plataforma Pro Acceso, que exige la promulgación en España de una ley de acceso a la información obrante en poder de la Administración. Su aspiración pasa por que la nueva regulación recoja los nueve principios de transparencia democrática que derivan de la nueva Convención del Consejo de Europa sobre el acceso a documentos oficiales (CONSEJO DE EUROPA, 2009: web) y de un estudio comparado de la legislación y el acceso a documentos administrativos en más de 80 países del mundo, que ha manejado este colectivo (www.proacceso.org/los-nueve-principios/). Entre dichos principios destaca el derecho de acceso de todos los ciudadanos a la información de modo sencillo, rápido, gratuito y sin necesidad de justificar razones; la dedicación de un cuerpo de funcionarios a la tramitación ágil de las solicitudes y la justificación por la Administración de los motivos en caso de denegación de una solicitud. Como punto central, esta plataforma reivindica un principio de igualdad de la información, por el que "toda información en poder de las administraciones, de todos los poderes del Estado y de todas aquellas entidades privadas que ejerzan funciones públicas debe ser pública" (COALICIÓN PRO ACCESO, 2008: web).

\section{El proteccionismo de los datos públicos en España}

La situación actual en España responde en este terreno de manera prioritaria a la mentalidad proteccionista antes criticada, que hace que se mantenga un manto de privacidad sobre las cuestiones de interés público, como son cuentas y declaraciones de los políticos. Todo ello, mientras, paradójicamente, los datos de los ciudadanos sí son conocidos por el Estado, como ocurre con los censos de población (no accesibles al público de manera directa y generalizada), o por empresas privadas como bancos, que poseen datos sobre nuestra insolvencia patrimonial (los ficheros de morosos). Tal contradicción refuerza el error de aplicar un proteccionismo unilateral y descompensado en el que los datos de los ciudadanos sean bien conocidos por el Estado mientras que el uso dado por la Administración a esos datos y la propia actividad de los representantes públicos no pueda ser fiscalizada en sentido inverso.

Para explicar dicho desajuste es interesante detenerse en la confusión entre el concepto de "interés público" y el de "interés general". Es habitual que se venda como información objetivamente importante para el funcionamiento de la sociedad o información de interés público (unas elecciones presidenciales) la que es en realidad mero entretenimiento o interés general de una amplia variedad de públicos (la vida privada de los hijos de los políticos) $)^{2}$.

${ }^{2}$ Para una distinción entre "interés público", "interés general” e interés particular y comercial de públicos más o menos amplios, junto con la diferencia entre "interés público" e "interés del público" o de los públicos, en el ámbito de la información periodística, véase por ejemplo HALLIN (1997). 
Frente a esto, los defensores de la privacidad y la intimidad denuncian, no sin razón, que muchos datos de carácter personal de los sujetos privados circulan entre empresas y por Internet sin control, discurso al que añaden la necesidad de la privacidad de cualquier dato de identificación personal, sin pararse a distinguir cuándo ciertos datos sobre personas y sus actividades constituyen en realidad un asunto público. El buen entendimiento del concepto de "interés público" nos llevaría a comprender la necesidad de proteger datos íntimos y al mismo tiempo dar publicidad a otros asuntos que identifican comportamientos individuales con una ineludible responsabilidad o trascendencia pública (por afectar a los derechos de equidad, seguridad, etc. del conjunto de la sociedad), como las listas de las notas de los alumnos de un centro, los opositores a un puesto público o los ingresos económicos de los políticos.

$\mathrm{Su}$ ocultismo sólo lleva a que se produzca un acceso unidireccional por parte de unos pocos encargados de custodiar tal información. Esto, según Reg WHITAKER (1999: 192) es un "irónico recurso si tenemos en cuenta que tanto las leyes que protegen la libertad de información como las que protegen la intimidad de los ciudadanos han sido promovidas por grupos de la sociedad civil para limitar el poder del Estado burocrático".

\section{Las "Freedom of information Acts"}

El control ciudadano de los asuntos públicos es considerado un asunto de primera importancia en muchos países democráticos, entre ellos EEUU, como prueban las diferentes leyes que regulan el acceso a cuestiones públicas. EEUU, a diferencia de España, es un país con tradición garantista de la autonomía privada y reducción de la presencia del Estado en los asuntos de la sociedad civil. Al mismo tiempo, el mismo sentido del liberalismo -el individuo tiene que tener recursos para defenderse de los abusos del Estado-, le lleva a permitir la transparencia de los asuntos públicos, sin proteccionismos que busquen limitar el acceso a la información.

El motivo puede explicarse mediante una frase recogida por Robert G. VAUGHN (2000: 14), profesor en la Escuela de Derecho de la American University, y pronunciada por James Madison, uno de los fundadores de la democracia estadounidense, además de su cuarto presidente: "Un gobierno popular sin información popular o los medios de adquirirla, no es sino el prólogo de una farsa o una tragedia o, tal vez, de ambas a la vez".

En lo referido al campo legislativo, EEUU ha fomentado, desde varias décadas atrás, la promoción de leyes de acceso a la información, comenzando por la Freedom of Information Act (FOIA, 1966) cuyo principio central establece que "la Administración ha de revelar la información que custodia a toda persona que lo solicite, con independencia de su condición, nacionalidad o motivo"3 (BANISAR, 2003: 86), como recoge este especialista en legislación sobre libertad de información. La FOIA aboga por el libre acceso y la obligatoriedad de justificación por la Administración en caso de negativa. Por el contrario en España, al ser la normalidad la restricción, es el interesado quien debe exponer un motivo para el acceso.

\footnotetext{
${ }^{3}$ Traducción propia.
} 
Esta ley ha sufrido diferentes actualizaciones, entre ellas la Electronic Freedom of information Act (EFOIA, 1996), que establece la obligación de entregar los documentos en cualquier formato solicitado; la SunSHINE ACT de 2006, que continúa profundizando en los principios de obligación de la Administración de facilitar al público la documentación en su poder; o la Openness Promotes Effectiveness in our National Government Act de 2007 (OpEn Government ACT, 2007), que promueve la inclusión de los medios de comunicación entre aquellos sujetos a quienes deben imponérsele cuotas menores de pago al solicitar una grabación o fichero, por no ser su interés de tipo comercial.

Concretamente en el tema que nos ocupa EEUU lleva la delantera, y la publicación de las finanzas de los funcionarios de gobierno y servidores públicos está totalmente regulada desde hace aproximadamente una década. El Gobierno se rige por una ley sobre ética de los representantes públicos que requiere que los miembros del Congreso, los jueces federales y ciertos funcionarios ejecutivos, sometan su información financiera a la libre consulta del público. En los informes facilitados al efecto están incluidos el ingreso por diferentes fuentes, dividendos, intereses, rentas y ganancias de capital, además de los regalos y la información sobre activos y pasivos. Para VAUGHN (2000), esta invasión en la intimidad personal se justifica por la necesidad de garantizar la honradez de los altos funcionarios, ya que de este modo se permite que los ciudadanos particulares puedan examinar los informes y comprobar que los funcionarios no confunden sus obligaciones ante el público con sus intereses financieros personales. Del mismo modo, esta revelación pública de los intereses económicos de los miembros del Gobierno es una importante muestra de la concienciación de los empleados públicos respecto de su labor ante los ciudadanos, que asumen como naturales los posibles dilemas con el derecho a la privacidad.

En Gran Bretaña la ley se muestra aperturista, al igual que en EEUU, pero sólo desde una fecha reciente. El Reino Unido aprobó en el año 2000 la Freedom of Information Act (BRITISH FREEDOM, 2000) que otorga el derecho de acceso a cualquier persona a la información contenida en el ámbito de las autoridades públicas. Sin embargo, enumera tres categorías de excepciones: En primer lugar figura la "absoluta", que engloba los archivos del Parlamento, información de y sobre servicios de seguridad y la obtenida confidencialmente o protegida bajo otra ley; en segundo lugar considera la "de clase cualificada", aplicada a la información referida a política gubernamental, a la seguridad nacional, investigaciones, comunicaciones de la Corona y privilegios legales; y por último establece la categoría de excepción "limitada", cuando el gobierno demuestra un perjuicio a los intereses legítimos de su actividad, como defensa, economía, prevención de crímenes, intereses comerciales etc.

Para comprobar cuándo aplicar las excepciones a esta Freedom of Information Act se utiliza el llamado test de interés público, según el cual "la información sólo puede permanecer oculta cuando el interés público en mantener la excepción supera el interés público en revelarlo"4 (BANISAR, 2003: 84). Ello demuestra la valoración del interés público presente en Gran Bretaña, priorizándolo al interés particular de la Administración cuando ésta apela a la protección de la privacidad de manera exagerada.

\footnotetext{
${ }^{4}$ Traducción propia
} 
En el caso de Francia existe desde 1978 la Ley de acceso a documentos administrativos, el equivalente francófono a las leyes anglosajonas de transparencia documental, que permite el derecho de acceso general a dichos documentos, entre los que se incluyen noticias, grabaciones, estadísticas, órdenes, instrucciones... en cualquier formato.

Sin embargo, se contemplan excepciones para documentos que dañen el secreto de los procedimientos del gobierno y las autoridades, de la defensa nacional, de la política exterior francesa, de la seguridad de estado... etc. Junto a éstos, la actualización en 2009 de la Ley de Informática, Ficheros y Libertades, restringió el acceso a los "datos personales, el origen racial o étnico, las opiniones políticas, filosóficas o la vida sexual de las personas"5 (Ley 78-17, 2009: art. 8. I). De lo anterior se deduce que aunque la legislación francesa no plantea un claro principio de equilibrio entre el derecho de acceso y el de protección a la privacidad, sí establece al menos una enumeración del tipo de archivos públicos considerados protegidos por razones de privacidad, así como el acceso a documentos que, pudiendo albergar aspectos privados, pueda justificarse su transparencia pública.

\section{La poca claridad y transparencia de nuestra legislación}

La Constitución Española reconoce la importancia de la posesión de información por los ciudadanos, equiparando implícitamente el derecho de información y participación con la calidad de la democracia. De este modo, en su artículo 20.d recoge el derecho "a comunicar o recibir libremente información veraz por cualquier medio de difusión" (CE, 1978: art.20.d). También en el artículo 105.b se asume la regulación del "acceso de los ciudadanos a los archivos y registros administrativos, salvo en lo que afecte a la seguridad y defensa del Estado, la averiguación de los delitos y la intimidad de las personas" (CE, 1978: art.105.b). No obstante, y como han puesto de relieve numerosos juristas, cuya argumentación sobrepasa en estas páginas el espacio que requeriría su exposición, el hecho de que el artículo 105 de nuestra constitución quede fuera del bloque de los derechos fundamentales ha facilitado que la interpretación legisladora hasta ahora dominante haya considerado el acceso a los documentos administrativos en inferioridad de consideración al de la privacidad e intimidad genéricas.

Las diferencias entre España y el resto de Europa en esta materia se vislumbran claramente tras el estudio comparativo entre las respectivas legislaciones. El resultado permite evidenciar que "España es el único país de la Unión Europea con más de un millón de habitantes que no tiene una ley específica del derecho de acceso a la información" (COALICIÓN PRO ACCESO, 2008: web).

Mientras en la Unión Europea, existen leyes generales de acceso a la información pública (como las antes referidas FOIA de Gran Bretaña o la Ley de Acceso a Documentos Públicos de Francia), en España sólo existen leyes sectoriales como la Ley 27/2006, que regula el Derecho de Acceso a la Información en Materia de Medio Ambiente, sin

\footnotetext{
${ }^{5}$ Traducción propia
} 
que el ciudadano tenga que declarar en este ámbito específico un interés determinado.

En sentido contrario están las leyes españolas que de manera general o parcial se ocupan de la "protección de Datos", de las que se puede decir que buena parte de la redacción está planteada de modo restrictivo, de forma que se da prevalencia a la protección sobre el acceso. Así ocurre en la Ley de Procedimiento Administrativo Común de 1992, que reserva la posibilidad de reclamación de dichos documentos sólo a "terceros que acrediten un interés legítimo directo". (LEY RÉGIMEN JURíDICO, 1992: art. 37.2). Del mismo modo reserva el derecho de acceso a archivos y registros al propio sujeto objeto del expediente "cuando contengan datos referentes a la intimidad de las personas”. (Idem 1992: art. 37). De igual forma, la Ley de Protección de Datos de Carácter Personal consagra el principio general del impedimento de acceso a ficheros de la Administración en cuanto incluyan datos personales y los aludidos no faciliten un consentimiento expreso para su revelación. Con muy escasas excepciones que afectan a las denominadas con carácter ultra restrictivo "fuentes de acceso público" (LOPD, 1999, art. 3,j) y algunos registros oficiales como el Mercantil y los de la Propiedad, la interpretación de la LOPD y el desarrollo reglamentario posterior de la Agencia Española de Protección de Datos ha llegado a considerar que los blogs o páginas webs que no sean estrictamente empresas periodísticas no constituyen "medios de comunicación" y no pueden revelar, por tanto, datos identificadores de personas sin el consentimiento previo de éstas (RODRíGUEZ, 2010).

Se introducen así dos borrosos conceptos: por un lado el de "interesado", que en la jurisprudencia española se emplea confusamente en sustitución del de afectado, y por otro lado el de "intimidad", que pone una barrera infranqueable al derecho de acceso, sin establecer límites o distinciones entre intimidad y privacidad. Tampoco contempla la legítima transformación en información pública de datos originalmente privados, al no apreciar que tan fundamentales como "el derecho al honor, la intimidad personal y familiar y la propia imagen" (que protege el art. 18 de la CE), son todos los demás "derechos y deberes fundamentales" recogidos en Título I. Lo cual implica la posibilidad de conflictos entre esos diferentes derechos de igual rango sin que pueda establecerse a priori la prevalencia sistemática de alguno de ellos.

\section{La apertura legislativa $₫$ El inicio del cambio?}

En el año 2006 se produce no obstante en España un cambio significativo, con la aprobación de la ley 5/2006 de 10 de abril de Regulación de conflictos de intereses de los miembros del Gobierno y de los Altos Cargos de la Administración General del Estado. Dicha ley, que supuso un hito para el control anticorrupción, demoró su entrada en vigor desde los cuatro meses previstos en el texto aprobado, hasta tres años.

Finalmente, el 15 de octubre de 2009, se adopta la Resolución de la Secretaría de Estado para la Función pública, por la que se da cumplimiento a lo dispuesto en el articulo 14.4 de la Ley 5/2005 sobre facilitación de acceso a los datos patrimoniales de los altos cargos del Ejecutivo, provocando una modificación importante en la situación de restricción y ambigüedad legal. En ella, se incluyen como cargos obligados a presentar sus declaraciones patrimoniales: el Presidente del Gobierno, los Ministros del Gobierno y los Secretarios de Estado. 
Sin embargo, cabe analizar una aparente contradicción en la redacción del contenido de la ley, reflejada en dos artículos. Por un lado está el artículo 14.3, en el que se recoge lo siguiente:

"El Registro de Bienes y Derechos Patrimoniales tendrá carácter reservado y solo podrán tener acceso al mismo, además del propio interesado, los siguientes órganos: El Congreso de los Diputados y el Senado [...], los órganos judiciales para la instrucción o resolución de procesos que requieran el conocimiento de los datos que obran en el Registro [...] y el Ministerio Fiscal cuando realice actuaciones de investigación...”. (LEY REGULACIÓN DE CONFLICTOS, 2006: art. 14.3)

Por el otro lado, y acto seguido, el artículo 14.4 establece:

"El contenido de las declaraciones de bienes y derechos patrimoniales de los miembros del Gobierno y de los Secretarios de Estado se publicarán en el «Boletín Oficial del Estado»...". (LEY REGULACIÓN DE CONFLICTOS, 2006: artículo 14.4).

Esta redacción es contradictoria, ya que denota la existencia de una diferencia entre el contenido del Registro de Bienes y Derechos Patrimoniales y las declaraciones publicadas en el BOE. Parece indicar un contenido más reducido en estas declaraciones respecto del Registro, como se analizará a continuación.

Durante el tiempo que medió entre el anuncio en 2004 por el Presidente del Gobierno, Rodríguez Zapatero, de su intención de publicar en el BOE el patrimonio de los mencionados altos cargos, hasta la fecha de su primera publicación el 15 de octubre de 2009, muchos grupos políticos seguían reclamando el cumplimiento de la propuesta.

El pleno del Congreso del 19 de noviembre de 2008 fue el lugar que eligieron varios de ellos para interpelar a la Ministra de Economía y Hacienda, Elena Salgado, que se excusaba así; "la posible publicación de los bienes de los altos cargos está en relación con sus declaraciones de Patrimonio y, como este impuesto está condenado a la supresión, el reglamento no se desarrollará hasta que el proyecto de ley que regula la supresión de dicha tasa culmine su tramitación en las Cortes" (EUROPA PRESS, 2008 a: web). Sus declaraciones dotaban al Gobierno de una baja credibilidad entre los diferentes grupos políticos, y la reacción no tarda en producirse en el mismo mes de noviembre: los diputados de ERC- IU- ICV, de la mano de Joan Herrera, plantean una moción. Entre sus argumentos destacan:

"Con reforma o sin ella, el Gobierno seguirá siendo titular de un determinado patrimonio o riqueza que ha de ser objeto de control y vigilancia, y la obligación del Gobierno es garantizar que los mecanismos que establece la Ley sean eficaces para la consecución de sus propios fines como son prevenir la existencia de conflictos de intereses y garantizar la transparencia, el comportamiento ético, la objetividad, la imparcialidad e independencia de los miembros del gobierno y de los altos cargos de la Administración General del Estado" (Europa Press, 2008b: web).

El PP también se suma a la reivindicación de la medida, presentando una Proposición No de Ley que, tras ser votada el 25 de octubre, recibe el respaldo unánime del Congreso. En consecuencia, el Gobierno asume el compromiso aunque negocia el plazo, y propone una enmienda para aumentar de tres a cuatro meses el tiempo del que 
dispondrá para presentar estos datos. Los tres o cuatro meses se convirtieron en un año hasta que, por fin, el 15 de octubre de 2009, el Gobierno de Rodríguez Zapatero cumple su promesa electoral y publica los datos de declaración de bienes y derechos patrimoniales de los miembros del Gobierno.

La presentación comprende:

ACTIVO

-Bienes inmuebles, incluyendo la descripción y el valor

- Otros bienes

PASIVO

Créditos, Préstamos Bancarios...

(BOE, 2009 sección III).

A partir de la publicación en el BOE de dichos datos, esta investigación comenzó con la elaboración de una tabla detallada de resultados de elaboración propia, en la que quedaban distribuidos por nombre, sexo, cargo, presentación o no de la declaración, activo declarado, bienes inmuebles, valores de otros bienes y pasivo declarado, el conjunto de las declaraciones de patrimonio de los miembros del Gobierno hechas públicas en el Boletín Oficial del Estado del 15 de octubre de 2009 (MINISTERIO DE LA PresidenCiA, 2009). A partir de esa tabla recopilatoria, y conforme a los principios de sistematización del periodismo de precisión, se ha generado una comprensión sintética y global del conocimiento de interés público que dichos datos aportan, tal y como reflejan los cuadros y gráfico expuestos y comentados en los epígrafes siguientes.

Pese a las carencias que pueda presentar esta divulgación, se puede concluir que recoge a grandes rasgos lo que son las cuentas básicas de cualquier ciudadano: un Activo genérico que recoge bienes inmuebles y otros bienes sin detallar, y unos fondos ajenos o exigibles del Pasivo. Los datos ausentes, como los fondos propios o no exigibles del pasivo, que sí se presentan en los balances empresariales, son importantes aunque no tan necesarios. Estos pueden deducirse calculando la diferencia entre el Activo total y los créditos y préstamos del Pasivo, ya que Activo y Pasivo deben totalizar lo mismo.

A partir de esta materia prima informativa comienza a vislumbrarse la aportación que en la labor de perro guardián de los asuntos públicos puede desarrollar el periodismo de precisión, al no limitarse, como en otras parcelas del periodismo convencional, a la recopilación de declaraciones de algunos sujetos o la recopilación coyuntural de observaciones aisladas o circunstancias fortuitas. Con un conjunto de información de alto interés noticioso que afecta a los principales representantes del Poder Ejecutivo, estructurada conforme a una serie de parámetros y variables y susceptible en consecuencia de ser cuantificada y categorizada de forma comparada, el ejercicio del periodismo de precisión puede extraer una información de segundo nivel, de alto valor, que no resultaría evidente por sí misma mediante la simple reproducción o alusión a los datos aislados de algunos de los sujetos incluidos en el citado fichero. Lo que sigue es el resultado, por tanto, de una aplicación propia de la perspectiva de esta nueva modalidad periodística al conjunto de datos accesible al público en el citado documento administrativo. Algo que, por el momento, no ha realizado ningún medio periodístico español del que se tenga constancia. 


\section{Un ejercicio de periodismo de precisión sobre las declaraciones patrimoniales del Gobierno}

Algunas aplicaciones analíticas que pueden realizarse son la comparativa entre diferentes variables, como por ejemplo, sexo y cargo político con declaración de bienes patrimoniales y/o pasivo. Se reflejan a continuación dos cuadros con cruces de datos por sexo y cargo con patrimonio y deudas, una forma gráfica de representación de datos que permite hacer una distribución numérica y sintética de las frecuencias acumuladas.

En un primer cuadro se consideran el sexo y el cargo como variables independientes o influyentes sobre el resto, siendo la variable dependiente el patrimonio, cuyas frecuencias se distribuyen a su vez en una horquilla económica desde 0 a 4.000 .000 euros. Esta determinación de variables responde a un criterio de antigüedad, que por lógica nos indica que las variables sociodemográficas son más antiguas que la del patrimonio. De este modo se entiende que el sexo o cargo de una persona puede determinar su patrimonio, pero su patrimonio nunca determina su sexo y difícilmente su cargo. Al estar este cuadro planteado en función de las variables de sexo y cargo, los datos están organizados para una lectura en vertical (lo que implica a su vez la comparación en horizontal, tal y como recomiendan la mayoría de especialistas en tablas y cuadros estadísticos para las ciencias sociales). De este modo podemos deducir, por ejemplo, que el $4 \%$ de los hombres pertenecientes al Gobierno declaran un patrimonio de entre 0 y 100.000 euros de activo frente al $18 \%$ de las mujeres que declaran ese mismo nivel de patrimonio. También, que el $6 \%$ de los ministros declaran bienes por valor de más de 4 millones de euros frente al $0 \%$ del de los secretarios que lo declaran.

\begin{tabular}{|l|c|c|c|c|c|c|}
\hline \multicolumn{3}{|c|}{ Cuadro 1: Distribución de bienes patrimoniales de los miembros del Gobierno por sexo y cargo } \\
(Octubre de 2009) \\
\hline & \multirow{2}{*}{ TOTAL } & \multicolumn{2}{c|}{ SEXO } & \multicolumn{3}{c|}{ CARGO } \\
\cline { 3 - 7 } & & Masculino & Femenino & Presidente & Ministro & Secretario \\
\hline Población & $43(100 \%)$ & $26(60 \%)$ & $17(40 \%)$ & $1(2 \%)$ & $17(40 \%)$ & $25(58 \%)$ \\
\hline Detalla bienes patrimoniales & $0 \%$ & $0 \%$ & $0 \%$ & $0 \%$ & $0 \%$ & $0 \%$ \\
\hline Entre 0 y $100.000 €$ & $4(9 \%)$ & $1(4 \%)$ & $3(18 \%)$ & $0 \%$ & $2(12 \%)$ & $2(8 \%)$ \\
\hline Entre 100.000 y $200.000 €$ & $9(21 \%)$ & $7(27 \%)$ & $2(12 \%)$ & $0 \%$ & $4(24 \%)$ & $5(20 \%)$ \\
\hline Entre 200.000 y $300.000 €$ & $8(18,5 \%)$ & $6(23 \%)$ & $2(12 \%)$ & $1(100 \%)$ & $3(18 \%)$ & $4(16 \%)$ \\
\hline Entre 300.000 y $400.000 €$ & $2(5 \%)$ & $2(8 \%)$ & $0 \%$ & $0 \%$ & $1(6 \%)$ & $1(4 \%)$ \\
\hline Entre 400.000 y $500.000 €$ & $6(14 \%)$ & $2(8 \%)$ & $4(24 \%)$ & $0 \%$ & $1(6 \%)$ & $5(20 \%)$ \\
\hline Entre 500.0000 y 1.000 .000 & $8(19 \%)$ & $3(12 \%)$ & $5(29 \%)$ & $0 \%$ & $3(18 \%)$ & $5(20 \%)$ \\
\hline Entre 1.000 .000 y 4.000 .000 & $5(12 \%)$ & $5(19 \%)$ & $0 \%$ & $0 \%$ & $2(12 \%)$ & $3(12 \%)$ \\
\hline Más de $4.000 .000 €$ & $1(2 \%)$ & $0 \%$ & $1(6 \%)$ & $0 \%$ & $1(6 \%)$ & $0 \%$ \\
\hline
\end{tabular}

En un segundo cuadro se toma igualmente como variables independientes el sexo y el cargo, pero considerando ahora como la variable dependiente el pasivo (deudas), cuyas frecuencias se distribuirían en una horquilla económica desde 0 a 1.000 .000 euros.

$\mathrm{Al}$ igual que ocurría en la tabla anterior, esta determinación de variables responde a un criterio de antigüedad, que por lógica nos indica que las variables sociodemográficas "sexo" y "cargo" son más antiguas que la de "deudas". De este modo se entiende que el sexo o cargo de una persona puede determinar sus deudas, pero su deuda 
nunca determina su sexo y difícilmente su cargo. De nuevo es de lectura vertical por lo que se puede extraer, por ejemplo, que el $42 \%$ de los miembros masculinos del Gobierno declaran 0 euros de deuda, frente al $24 \%$ de miembros femeninos que lo hacen, o que mientras el Presidente del Gobierno declara una deuda entre 0 y 100.000 euros, el $18 \%$ de los ministros y el $36 \%$ de los secretarios declaran esta misma cantidad.

\begin{tabular}{|l|c|c|c|c|c|c|}
\hline \multicolumn{2}{|c|}{ Cuadro 2: Distribución de Deuda ("pasivo") de los miembros del Gobierno por sexo y cargo } \\
(Octubre de 2009) \\
\hline
\end{tabular}

Aunque el reducido número de casos implicados en el análisis resta significación estadística a los resultados, la visión sintética de los datos permite extraer algunas curiosidades de interés noticioso para el conocimiento general de la ciudadanía. Resulta así, por ejemplo, en el caso de los patrimonios declarados, que, mientras el $47 \%$ de los varones reconocen patrimonios superiores a 300.000 euros, son el 59\% de las mujeres del colectivo las que se sitúan en esa franja superior a los 300.000 euros. Quizá resultará aún más llamativo para la percepción popular que desde el punto de vista del tipo de cargo, mientras el $48 \%$ de los ministros mencionan un patrimonio superior a los 300.000 euros, se declaran en esa situación el 56\% de los secretarios.

Respecto a las deudas, mientras el $12 \%$ de los varones declaran un débito superior a los 300.000 euros, son el $18 \%$ de las mujeres las que enfrentan esa situación. En cuanto a cargos, el $12 \%$ de los ministros asumen deudas superiores a los 300.000 euros frente al $16 \%$ de los secretarios. En consecuencia, y aún teniendo presente la ya comentada escasa consistencia de las diferencias para un grupo de datos tan reducidos, se aprecia una ligera tendencia entre las mujeres y los cargos de secretario de Estado a tener mayor patrimonio y también mayores deudas, frente a sus contrapartes, los hombres y los ministros.

Otro de los interesantes cálculos que cabe realizar en el marco de este análisis de datos es el del patrimonio y deuda promedio de los miembros del Gobierno. En el caso del patrimonio, la media es de $594.047,8$ mientras que la deuda media es 122.809,08 euros.

Es preciso tener en cuenta que al ser la media el resultado de la suma de todos los casos dividida entre el número de éstos, se convierte en "una medida intuitivamente satisfactoria de la tendencia central" (MEYER, 1993:80). Sin embargo, existen situaciones en las que unos pocos casos son radicalmente diferentes al resto y sesgan la media de manera acusada cuando el conjunto de casos es pequeño, como ocurre aquí 
con el patrimonio de 4.978.217,39 de Cristina Garmendia o la deuda de 815.500 de José Manuel Campa (según se verá más adelante).

Para estas situaciones se considera de mayor interés estadístico la mediana, definida como "el valor del caso que queda en el medio" (MEYER, ibid), que es la cifra correspondiente al elemento de la serie ordenada de casos que deja la mitad de los casos por encima de él y la otra mitad por debajo.

De este modo, la mediana del patrimonio de los miembros del Gobierno y secretarios es de $364.869,33$, mientras que la mediana de la deuda es $40.148,76$, cifras sensiblemente inferiores a las computadas mediante la media aritmética, y que cabría considerar más expresivas de la situación promedio de los altos cargos analizados.

\section{La correlación entre variables: El gráfico de dispersión y la recta de regresión lineal sobre los datos analizados}

Una vez examinados los cruces de datos, es interesante establecer una correlación entre los datos cuantitativos disponibles: patrimonio y deudas. Dicha correlación permite observar la asociación existente entre el patrimonio que posee un miembro del gobierno y su deuda, pudiendo establecer si dicha correlación es positiva (a más patrimonio, mas deuda) o negativa (a más patrimonio menos deuda o a menos patrimonio más deuda).

Para ordenar la distribución de la posible correlación se calcula la llamada recta de regresión lineal cuyo paso previo consiste en la realización de un gráfico de dispersión. Esta regresión lineal permite conocer cuál es la línea recta que más cerca pasa de todos los puntos que representan la posición de cada caso analizado en el eje de intersección entre la magnitud de los patrimonios y la de las deudas. Ello permite observar además cuales son los casos aberrantes, o "outliers" en la terminología estadística anglosajona, (que se salen de lo común o alejan de manera extraordinaria respecto al promedio de una variable). Pero en el caso de un estudio de correlaciones, los casos aberrantes o "outliers" en términos periodísticos serán además los que se aparten de manera más contradictoria del patrón de relaciones existentes entre patrimonio y gastos de los altos cargos estudiados. En términos visuales serán aquellos puntos que aparezcan más alejados del transcurso de la recta de regresión lineal ${ }^{6}$. La citada recta expresa, además, cuál sería la situación ideal en la que cada variación de la variable independiente se correspondería con otra variación estandarizada de la variable dependiente. Su fórmula de cálculo es $\mathrm{y}=\mathrm{a}+\mathrm{bx}$, siendo

$$
\begin{aligned}
\mathrm{b} & =\frac{\sum(\mathrm{X}-\bar{X})(\mathrm{Y}-\bar{Y})}{\sum(\mathrm{X}-\bar{X})^{2}} \\
\mathrm{a} & =\bar{Y}-\mathrm{b} \bar{X}
\end{aligned}
$$

Para su resolución en el análisis que nos ocupa resulta necesario, en primer lugar, calcular los puntos a y b, mediante el proceso condensado en el Cuadro 3:

${ }^{6}$ Para apreciar la importancia analítica de los casos aberrantes, según se sitúen cerca o lejos de la recta de regresión lineal, cfr. por ejemplo, el epígrafe sobre "Effect of Outliers" en STOCKBURGER (1998: web). 


\begin{tabular}{|c|c|c|c|c|c|c|c|}
\hline \multicolumn{8}{|c|}{$\begin{array}{c}\text { Cuadro 3: Cálculo de las distancias de cada caso analizado (miembros del gobierno) respecto a las medias } \\
\text { aritméticas de las variables Patrimonio (x) y Deuda (y). }\end{array}$} \\
\hline Nombre del alto cargo & $\begin{array}{c}\mathbf{X}= \\
\text { patrimonio }\end{array}$ & $\begin{array}{c}Y= \\
\text { deudas }\end{array}$ & $(\mathbf{X i}-\bar{X})$ & $(\mathbf{Y i}-\bar{Y})$ & $(\mathbf{X i}-\bar{X}) *(\mathbf{Y i}-\bar{Y})$ & $(\mathrm{Xi}-\bar{X})^{\wedge} \mathbf{2}$ & $\begin{array}{c}\text { Coeficiente } \\
\text { de } \\
\text { garantía }\end{array}$ \\
\hline $\begin{array}{l}\text { Aído Almagro, } \\
\text { Bibiana }\end{array}$ & $38.918,65$ & $109.722,39$ & $-555.129,25$ & $-13.086,69$ & 7.264.804.499 & 308.168 .481 .262 & 0,35 \\
\hline $\begin{array}{l}\text { Almunia Badía, } \\
\text { Eva }\end{array}$ & $84.979,37$ & $26.943,69$ & $-509.068,53$ & $-95.865,40$ & 48.802 .056 .054 & 259.150 .770 .628 & 3,15 \\
\hline $\begin{array}{l}\text { Blanco López, } \\
\text { José }\end{array}$ & $239.536,02$ & $241.138,21$ & $-354.511,88$ & $118.329,13$ & -41.949 .081 .939 & 125.678 .671 .181 & 0,99 \\
\hline $\begin{array}{l}\text { Caamaño Domín- } \\
\text { guez, Francisco }\end{array}$ & $106.703,61$ & $36.300,00$ & $-487.344,29$ & $-86.509,08$ & 42.159 .706 .055 & 237.504 .454 .412 & 2,94 \\
\hline $\begin{array}{l}\text { Camacho Vizca- } \\
\text { íno, Antonio }\end{array}$ & $113.908,73$ & $454.173,67$ & $-480.139,17$ & $331.364,59$ & -159.101 .118 .220 & 230.533 .620 .022 & 0,25 \\
\hline $\begin{array}{l}\text { Campa Fernández, } \\
\text { José Manuel }\end{array}$ & $2.018 .587,00$ & $815.500,00$ & $1.424 .539,10$ & $692.690,92$ & 986.765 .301 .260 & 2.029.311.654.982 & 2,48 \\
\hline $\begin{array}{l}\text { Campo Moreno, } \\
\text { Juan Carlos }\end{array}$ & $159.063,54$ & 0,00 & $-434.984,36$ & $-122.809,08$ & 53.420 .028 .842 & 189.211 .391 .138 & \\
\hline $\begin{array}{l}\text { Carlos Zarrías, } \\
\text { Gaspar }\end{array}$ & $487.262,39$ & 0,00 & $-106.785,51$ & $-122.809,08$ & 13.114 .229 .940 & 11.403 .144 .580 & \\
\hline $\begin{array}{l}\text { Chacón Piqueras, } \\
\text { Carme María }\end{array}$ & $156.718,87$ & $358.382,27$ & $-437.329,03$ & $235.573,19$ & -103.022 .993 .950 & 191.256 .678 .162 & 0,44 \\
\hline $\begin{array}{l}\text { Chaves González, } \\
\text { Manuel }\end{array}$ & $68.964,29$ & 0,00 & $-525.083,61$ & $-122.809,08$ & 64.485 .034 .864 & 275.712 .794 .706 & \\
\hline $\begin{array}{l}\text { Corbacho Chaves, } \\
\text { Celestino }\end{array}$ & $208.017,52$ & $170.935,79$ & $-386.030,38$ & $48.126,70$ & -18.578 .370 .243 & 149.019 .456 .096 & 1,22 \\
\hline $\begin{array}{l}\text { Corredor Sierra, } \\
\text { Beatriz }\end{array}$ & $560.820,64$ & $283.981,15$ & $-33.227,26$ & $161.172,07$ & -5.355 .305 .840 & 1.104 .050 .631 & 1,97 \\
\hline $\begin{array}{l}\text { Espinosa Man- } \\
\text { gana, Elena }\end{array}$ & $400.038,08$ & 0,00 & $-194.009,82$ & $-122.809,08$ & 23.826 .167 .225 & 37.639 .809 .228 & \\
\hline $\begin{array}{l}\text { Fernández de la } \\
\text { Vega Sanz, } \\
\text { M Teresa }^{\mathrm{a}} \text { Te }\end{array}$ & $731.506,11$ & $161.717,88$ & $137.458,21$ & $38.908,80$ & 5.348.334.072 & 18.894 .760 .225 & 4,52 \\
\hline $\begin{array}{l}\text { Francisco Herrero, } \\
\text { José Luis de }\end{array}$ & $145.118,63$ & $201.976,63$ & $-448.929,27$ & $79.167,55$ & -35.540 .630 .115 & 201.537.487.082 & 0,72 \\
\hline $\begin{array}{l}\text { Gabilondo Pujol, } \\
\text { Ángel }\end{array}$ & $161.573,11$ & $8.482,19$ & $-432.474,78$ & $-114.326,89$ & 49.443.497.199 & 187.034 .439 .098 & 19,05 \\
\hline $\begin{array}{l}\text { Garmendia Mendi- } \\
\text { zábal, Cristina }\end{array}$ & $4.978 .217,39$ & $581.347,78$ & $4.384 .169,49$ & $458.538,70$ & 2.010.311.378.720 & 19.220 .942 .140 .293 & 8,56 \\
\hline $\begin{array}{l}\text { Goicoechea Gon- } \\
\text { zález, Nieves }\end{array}$ & $65.087,41$ & $87.708,15$ & $-528.960,49$ & $-35.100,93$ & 18.567 .005 .162 & 279.799.197.176 & 0,74 \\
\hline $\begin{array}{l}\text { Gomis Bernal, } \\
\text { Carmen }\end{array}$ & $431.393,24$ & 0,00 & $-162.654,66$ & $-122.809,08$ & 19.975 .468 .865 & 26.456 .537 .557 & \\
\hline
\end{tabular}




\begin{tabular}{|c|c|c|c|c|c|c|c|}
\hline Nombre del alto cargo & $\begin{array}{c}\mathrm{X}= \\
\text { patrimonio }\end{array}$ & $\begin{array}{c}Y= \\
\text { deudas }\end{array}$ & $(\mathbf{X i}-\bar{X})$ & $(\mathbf{Y i}-\bar{Y})$ & $(\mathrm{Xi}-\bar{X}) *(\mathrm{Yi}-\bar{Y})$ & $(\mathrm{Xi}-\bar{X})^{\wedge} 2$ & $\begin{array}{c}\text { Coeficiente } \\
\text { de } \\
\text { garantía }\end{array}$ \\
\hline $\begin{array}{l}\text { González-Sinde } \\
\text { Reig, Ángeles }\end{array}$ & $269.359,37$ & $72.843,34$ & $-324.688,53$ & $-49.965,74$ & 16.223 .302 .614 & 105.422 .639 .792 & 3,70 \\
\hline $\begin{array}{l}\text { Granado Martí- } \\
\text { nez., Octavio José }\end{array}$ & $155.565,00$ & 0,00 & $-438.482,90$ & $-122.809,08$ & 53.849 .681 .321 & 192.267 .251 .267 & \\
\hline $\begin{array}{l}\text { Gutiérrez del Cas- } \\
\text { tillo, Concepción }\end{array}$ & $459.094,77$ & $88.000,00$ & $-134.953,13$ & $-34.809,08$ & 4.697.594.238 & 18.212 .346 .581 & 5,22 \\
\hline $\begin{array}{l}\text { Iranzo Gutiérrez, } \\
\text { Silvia }\end{array}$ & $993.250,00$ & 0,00 & $399.202,10$ & $-122.809,08$ & -49.025 .643 .053 & 159.362 .318 .761 & \\
\hline $\begin{array}{l}\text { Jiménez García- } \\
\text { Herrera, Trinidad }\end{array}$ & $109.796,92$ & $183.854,59$ & $-484.250,98$ & $61.045,51$ & -29.561 .347 .768 & 234.499 .009 .063 & 0,60 \\
\hline $\begin{array}{l}\text { Laiglesia y Gonzá- } \\
\text { lez de Peredo, } \\
\text { Juan Pablo de }\end{array}$ & $584.903,24$ & $19.756,79$ & $-9.144,66$ & $-103.052,29$ & 942.377 .883 & 83.624 .758 & 29,61 \\
\hline $\begin{array}{l}\text { López Garrido, } \\
\text { Diego }\end{array}$ & $364.869,33$ & 0,00 & $-229.178,57$ & $-122.809,08$ & 28.145 .209 .065 & 52.522 .815 .732 & \\
\hline $\begin{array}{l}\text { Lossada Torres- } \\
\text { Quevedo, Ángel }\end{array}$ & $427.232,75$ & 0,00 & $-166.815,15$ & $-122.809,08$ & 20.486 .414 .815 & 27.827 .293 .385 & \\
\hline $\begin{array}{l}\text { Marín Uribe, } \\
\text { Pedro Luis }\end{array}$ & $124.507,03$ & 0,00 & $-469.540,87$ & $-122.809,08$ & 57.663 .882 .051 & 220.468 .626 .111 & \\
\hline $\begin{array}{l}\text { Martínez Alonso, } \\
\text { Carlos }\end{array}$ & $676.352,03$ & $40.148,76$ & $82.304,13$ & $-82.660,32$ & -6.803 .285 .961 & 6.773 .970 .251 & 16,85 \\
\hline $\begin{array}{l}\text { Méndez Martínez, } \\
\text { Constantino }\end{array}$ & $229.249,00$ & $37.950,00$ & $-364.798,90$ & $-84.859,08$ & 30.956 .498 .899 & 133.078 .235 .507 & 6,04 \\
\hline $\begin{array}{ll}\text { Mesquida } & \text { Fe- } \\
\text { rrando, Juan } & \end{array}$ & $219.145,00$ & $77.478,00$ & $-374.902,90$ & $-45.331,08$ & 16.994 .753 .319 & 140.552 .182 .441 & 2,83 \\
\hline $\begin{array}{l}\text { Moratinos Cu- } \\
\text { yaubé, } \\
\text { Miguel Ángel }\end{array}$ & $384.978,37$ & 0,00 & $-209.069,53$ & $-122.809,08$ & 25.675 .636 .358 & 43.710 .067 .266 & \\
\hline $\begin{array}{l}\text { Morlán Gracia, } \\
\text { Victor }\end{array}$ & $230.009,75$ & $28.355,81$ & $-364.038,15$ & $-94.453,27$ & 34.384 .593 .506 & 132.523 .772 .725 & 8,11 \\
\hline $\begin{array}{l}\text { Ocaña y Pérez de } \\
\text { Tudela, Carlos }\end{array}$ & $577.900,78$ & $356.198,07$ & $-16.147,12$ & $233.388,99$ & -3.768 .559 .406 & 260.729 .399 & 1,62 \\
\hline $\begin{array}{l}\text { Pérez Rubalcaba, } \\
\text { Alfredo }\end{array}$ & $1.223 .154,85$ & 0,00 & $629.106,95$ & $-122.809,08$ & -77.260 .046 .223 & 395.775 .557 .874 & \\
\hline $\begin{array}{l}\text { Puxeu Rocamora, } \\
\text { Josep }\end{array}$ & $1.863 .344,68$ & 0,00 & $1.269 .296,78$ & $-122.809,08$ & -155.881 .170 .420 & 1.611 .114 .322 .449 & \\
\hline $\begin{array}{l}\text { Ribera Rodríguez, } \\
\text { Teresa }\end{array}$ & $211.023,00$ & $50.000,00$ & $-383.024,90$ & $-72.809,08$ & 27.887 .690 .482 & 146.708.071.989 & 4,22 \\
\hline $\begin{array}{l}\text { Rodríguez Ramos, } \\
\text { Soraya }\end{array}$ & $403.305,55$ & $225.000,00$ & $-190.742,35$ & $102.190,92$ & -19.492 .135 .914 & 36.382 .643 .072 & 1,79 \\
\hline $\begin{array}{l}\text { Rodríguez Zapa- } \\
\text { tero, José Luis }\end{array}$ & $209.206,21$ & $80.847,89$ & $-384.841,68$ & $-41.961,19$ & 16.148 .415 .126 & 148.103 .122 .012 & 2,59 \\
\hline
\end{tabular}




\begin{tabular}{|c|c|c|c|c|c|c|c|}
\hline Nombre del alto cargo & $\begin{array}{c}\mathrm{X}= \\
\text { patrimonio }\end{array}$ & $\begin{array}{c}\mathbf{Y}= \\
\text { deudas }\end{array}$ & $(\mathbf{X i}-\bar{X})$ & $(\mathbf{Y i}-\bar{Y})$ & $(\mathbf{X i}-\bar{X})^{*}(\mathbf{Y i}-\bar{Y})$ & $(\mathrm{Xi}-\bar{X})^{\wedge} 2$ & $\begin{array}{c}\text { Coeficiente } \\
\text { de } \\
\text { garantía }\end{array}$ \\
\hline $\begin{array}{l}\text { Ros Perán, } \\
\text { Francisco }\end{array}$ & $1.473 .420,99$ & $116.910,06$ & $879.373,09$ & $-5.899,02$ & -5.187 .439 .666 & 773.297.036.079 & 12,60 \\
\hline $\begin{array}{l}\text { Rumí Ibáñez, } \\
\text { Mª Consuelo }\end{array}$ & $518.407,37$ & $365.137,35$ & $-75.640,53$ & $242.328,27$ & -18.329 .838 .117 & 5.721 .489 .378 & 1,42 \\
\hline $\begin{array}{l}\text { Salgado Méndez, } \\
\text { Elena }\end{array}$ & $976.934,00$ & 0,00 & $382.886,10$ & $-122.809,08$ & -47.021 .890 .100 & 146.601 .767 .603 & \\
\hline $\begin{array}{l}\text { Sebastián Gascón, } \\
\text { Miguel }\end{array}$ & $1.702 .635,00$ & 0,00 & $1.108 .587,10$ & $-122.809,08$ & -136.144 .562 .434 & 1.228 .965 .364 .165 & \\
\hline Medias & $594.047,90$ & $122.809,08$ & & & $\begin{array}{c}\text { suma de la } \\
\text { columna }\end{array}$ & $\begin{array}{l}\text { suma de la } \\
\text { columna }\end{array}$ & \\
\hline & & & & & 2.765 .515 .643 .066 & 29.940 .593 .796 .121 & \\
\hline & & & & $\mathrm{b}$ & 0,09 & \multirow{3}{*}{\multicolumn{2}{|c|}{$\begin{array}{l}\text { parámetros de la recta de re- } \\
\text { gresión lineal según expresión } \\
y=a+b x\end{array}$}} \\
\hline & & & & & & & \\
\hline & & & & a & 67938,80 & & \\
\hline
\end{tabular}

Una vez hallados los valores de a y $\mathrm{b}$, puede ya calcularse el valor matemático para dos puntos concretos del eje de la variable dependiente (la y ó deuda) correspondientes a dos valores concretos de la variable independiente (la x ó patrimonio), al partir del supuesto de que el nivel de patrimonio determinará el nivel de deuda contraída. Como el conocimiento de dos puntos por los que transcurre una recta resulta suficiente para su proyección al infinito, queda ya obtenida así la recta de regresión que, para el análisis desarrollado genera la regresión lineal que se expresa en el Grafico 1:

GRAFICO 1: Recta de regresión lineal de la relación entre patrimonio y deuda de los miembros del gobierno con declaración publicada el 15 de octubre de 2009

\section{RELACIÓN PATRIMONIO - DEUDAS MIEMBROS GOBIERNO}

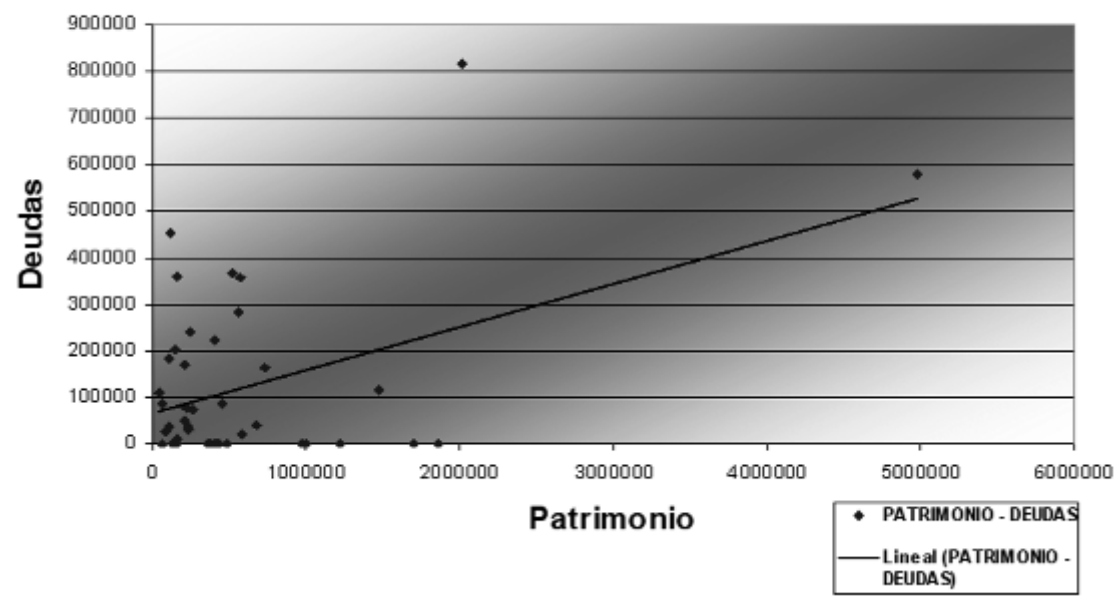


La recta obtenida en conexión con la nube de dispersión de los puntos reales reflejados en el gráfico parece presentar una correlación positiva (asciende de izquierda a derecha) ya que cada incremento de la variable x responde a un incremento de la variable y. Esto significaría que, en el conjunto de los altos cargos analizados, a mayor patrimonio, mayor cantidad de deuda contraída. Sin embargo es preciso comprobar la apariencia visual de este resultado mediante el cálculo del Coeficiente de Correlación según el test $r$ de Pearson $\left(\mathrm{y}^{2}\right)$. Éste da como resultado 0,437 , un valor moderado, insuficientemente alejado del cero a efectos de relevancia en la correlación, lo que corrobora que la correlación estadística entre ambas variables no es intensa. De hecho, al tratarse de un conjunto de datos muy pequeño, la consistencia y coeficiente de probabilidad de esta hipotética correlación tampoco resultan muy altos, al influir mucho sobre los resultados globales el valor numérico de los casos más alejados de la tendencia central. ${ }^{7}$ Traducido al asunto estudiado, significa que, si bien se aprecia una tendencia global a que los altos cargos con mayor patrimonio hayan sido los que muestran un mayor nivel de deuda, esa tendencia analizada en su conjunto resulta moderada, existiendo en concreto bastantes casos que no se ajustan a la tendencia general expresada.

Esto explica que el comportamiento de buena parte de los políticos individuales integrados en el análisis no responde a la pauta de su recta teórica de regresión lineal, ya que la nube de puntos de su alrededor presenta una dispersión aleatoria, al no estar las variables patrimonio y deuda altamente correlacionadas. Como consecuencia del ya indicado fuerte peso sobre el promedio en un pequeño conjunto de los casos aberrantes cabe concluir que es posible y útil establecer cuál sería la correlación perfecta entre el valor del patrimonio y el de deuda para cada uno de los miembros del Gobierno estudiado. Pero la realidad es que la dispersión mayoritariamente circular que se observa nos indica que las situaciones de los altos cargos estudiados resultan bastante dispares (en términos estadísticos se diría que la relación entre la recta de regresión lineal y la dispersión de los puntos sobre los que aquella se traza presenta un mal ajuste, como corresponde a una distancia grande respecto a las medias de los valores de $\mathrm{X}$ e $\mathrm{Y}$ en comparación con una dispersión total de los puntos no muy elevada según explican GonicK y SMiTH, (1999: 193 y ss.). En términos más concretos significa que hay una alta variabilidad entre altos cargos con grandes patrimonios y pequeñas deudas y otros con deudas elevadas en proporción a pequeños patrimonios, como por otra parte parece natural que corresponda a las diferentes situaciones vitales, en función por ejemplo de la antigüedad de las hipotecas contraídas por cada uno en relación al valor consignado para los bienes adquiridos.

Se pueden destacar como casos más aberrantes en primer lugar el de la ministra de ciencia e Innovación Cristina Garmendia, quien declara poseer un patrimonio de

\footnotetext{
${ }^{7}$ Como indica Idoia PoRTilla (2004:218), para un análisis de correlación sobre un conjunto comprendido entre 40 y 50 pares de datos, el valor mínimo del coeficiente de r, para empezar a considerar una hipótesis de interdependencia, a un nivel de fiabilidad del 95\%, debería estar en torno o por encima del 0,300. Como se recordará, en el análisis realizado el cómputo obtenido ha sido de 0,437 , lo que si bien supera el límite señalado por esta autora, no se aleja de él en exceso.
} 
4.978.217,38 euros y una deuda de sólo 581.437,78 (para el elevado nivel de patrimonio que declara). Su caso puede calificarse de aberrante porque al poseer tanto patrimonio y por tanto estar muy alejado por la derecha en la variable de las $\mathrm{x}$, modifica la trayectoria de la recta de regresión hacia la derecha. Sin embargo, si éste fuera un estudio donde hubiera correlación real, este punto no sería aberrante, pues no modificaría la trayectoria de la recta. El otro punto aberrante es el del Secretario de Estado de Economía José Manuel Campa Fernández, que con un patrimonio de 2.018.587 euros presenta deudas por valor de 815.500 euros. Estos dos casos indican las circunstancias más atípicas, por entenderse como lo menos habitual que tengan tan poca deuda para tan elevado patrimonio, en el primer caso, y una deuda tan desproporcionadamente elevada en comparación al resto de altos cargos estudiados, en el segundo. En sentido inverso despuntan por este orden el Secretario de Estado del Medio Rural y Agua, Josep Puxeu Rocamora, con un patrimonio de 1.863.344 euros; el Ministro de Industria Turismo y Comercio, Miguel Sebastián Gascón, con un patrimonio de 1.702.635 euros, y el Ministro del Interior, Alfredo Pérez Rubalcaba, con un patrimonio de 1.223.154 euros, en los tres casos sin tener computados un solo euro de pasivo o deuda.

Para establecer conclusiones relevantes serían necesarias averiguaciones complementarias, propias ya del periodismo de investigación tradicional, que desvelasen si esta distancia entre variables podría ser fruto de alguna irregularidad o deberse a situaciones explicables.

Por ejemplo, el exceso de patrimonio y ausencia de deudas, puede deberse a una hipoteca o hipotecas ya terminadas de pagar o de fortunas de origen familiar (como sucede en el caso de la ministra Cristina Garmendia). En sentido contrario, en el caso de quien contrasta un endeudamiento muy elevado para un patrimonio actualmente de valoración escasa, se podría asociar a la circunstancia pasajera de un fuerte endeudamiento respecto a bienes con expectativa de muy alta rentabilidad (compra de acciones a bajo precio mediante voluminosos préstamos pero con la expectativa de que esos valores bursátiles incrementen en gran medida su cotización).

En cualquier caso, estas cuestiones resultarían ya rastreables mediante el empleo de la investigación periodística convencional, si bien, la pista y evidencia de su interés público viene aportada por la aplicación del periodismo de precisión.

\section{La distancia a la quiebra de los cargos públicos}

Pero todavía el periodismo de precisión aplicado a este seguimiento puede aportar algún criterio adicional para extraer conclusiones sobre la salud de las cuentas de los miembros del Gobierno, mediante la aplicación del llamado coeficiente de garantía o de distancia a la quiebra, una ratio que nos informa de la totalidad de los activos reales de que dispone un sujeto para hacer frente al pago de su pasivo exigible íntegro. Ésta se calcula dividiendo el activo real entre las deudas totales, y su resultado nos informa acerca de la distancia a la quiebra en la que se encuentra una persona.

Si ratio $>1$, existen activos suficientes para hacer frente a los créditos.

Si ratio $=1$, el patrimonio es igual a las deudas.

Si ratio $<1$, existe una situación de quiebra técnica. 
Conocidos los datos, se pueden establecer tres grupos:

El formado por los que su ratio es mayor que 1. En este grupo estarían incluidos, de mejor a peor situación: Juan Pablo González de LaIglesia, con una ratio de 29,605, Ángel Gabilondo Pujol $(19,048)$, Carlos Martínez Alonso (16,846), Francisco Ros Perán $(12,603)$, Cristina Garmendia Mendizábal $(8,563)$, Víctor Morlán García $(8,111)$, Constantino Méndez Martínez (6,040), Concepción Gutiérrez del Castillo $(5,216)$, María Teresa Fernández de la Vega Sanz $(4,523)$, Teresa Ribera Rodríguez $(4,220)$, Ángeles González Sinde (3,697), Eva Almunia Badía (3,153), Francisco Caamaño $(2,939)$, Juan Mesquida Ferrando $(2,828)$, el presidente del Gobierno Rodríguez Zapatero $(2,587)$, José Manuel Campa Fernández $(2,475)$, Beatriz Corredor Sierra $(1,974)$, Soraya Rodríguez Ramos $(1,792)$, Carlos Ocaña $(1,622414125)$, María Consuelo Rumi Ibáñez $(1,419)$ y Celestino Corbacho Chaves $(1,216)$.

El formado por los que su ratio es menor que 1. En este grupo están los casos más complicados, el de aquellos cuyo activo no es suficiente para pagar sus deudas y se encuentran en una situación de quiebra técnica. El grupo está encabezado por quien presenta una ratio más alejada del 1, el Secretario de Estado de Seguridad, Antonio Camacho Vizcaíno $(0,250)$, seguido de la entonces Ministra de Igualdad, Bibiana Aído Almagro $(0,354)$, la Ministra de Defensa Carme Chacón $(0,437)$, la entonces Ministra de Sanidad y Política Social, Trinidad Jiménez García $(0,597)$, el Secretario de Estado de Secretario de Estado de Asuntos Constitucionales y Parlamentarios José Luis Francisco Herrero $(0,718)$, la Secretaria de Estado de Comunicación, Nieves Goicoechea $(0,742)$, y finalmente, el Ministro de Fomento, José Blanco López $(0,993)$. Se requeriría de nuevo un seguimiento posterior mediante el tradicional periodismo de investigación para aclarar las circunstancias reales que explicaran la causa de cada una de estas preocupantes ratios, atribuibles sin duda a diversos factores, como escrituración de viviendas sensiblemente por debajo del valor de mercado y del de las hipotecas contraídas, etc.

Finalmente queda el grupo formado por quienes no presentan desequilibrio alguno entre sus deudas y patrimonio y, en consecuencia, no se les puede aplicar la ratio de garantía (al ser imposible dividir entre cero). Su solvencia es evidente e incluso superior a la de los consignados en el primer grupo. En este nivel están el Secretario de Estado del Medio Rural y Agua, Josep Puxeu Rocamora, el Ministro del Interior, Alfredo Pérez Rubalcaba, y el entonces Ministro de Asuntos Exteriores y Cooperación, Miguel Ángel Moratinos. Lo mismo ocurre con Ángel Losada Torres-Quevedo, Diego López Garrido, Juan Carlos Campo Moreno, Elena Salgado Méndez, Octavio José Granadao Martínez, Miguel Sebastián Gascón, Silvia Iranzo Gutiérrez, Pedro Luis Martín Uribe, Elena Espinosa Mangana, Carmen Gomis Bernal, Manueal Chaves González y Gaspar Carlos Zarrías Arévalo.

Mediante este otro enfoque se corrobora que la mejor situación económica es la del Secretario de Estado de Medio Rural y Agua Josep Puxeu Rocamora, con un patrimonio de 1.863.344,60 y una deuda de 0. Por otro lado, de entre aquellos que tienen algo de deuda, la situación económica más positiva es la del Secretario de Estado para Iberoamérica Juan Pablo González de La Iglesia, que por cada euro que debe, posee 29,60 para hacerle frente. En el otro extremo (encabezando la peor situación) se en- 
cuentra el secretario de seguridad Antonio Camacho Vizcaíno que, por cada euro que debe, sólo puede hacerle frente con 0,25 .

Como puede comprobarse, el manejo y comparación de estos diferentes datos produciría, de llegar a publicarse en algún medio de comunicación, un variado conjunto de noticias y despieces, que generarían, sin duda, jugosos titulares, además de aportar a los ciudadanos una percepción mucho más comprensiva que la facilitada en primera instancia por la simple publicación de unos datos en el Boletín Oficial del Estado.

\section{Un avance con lagunas}

Toda la trayectoria española de obstruccionismo al acceso a datos administrativos parece tener su punto de inflexión en 2009, con la aparición de la Resolución de la Secretaría de Estado del 15 de Octubre, que permite abrir a una cierta contemplación pública la declaración de patrimonio del Gobierno (junto a otras declaraciones de actividades de Gobierno y Congreso, respectivamente).

Sin embargo, un análisis más detenido de la propia regulación y del contenido de los datos accesibles produce la evidencia de que la transparencia establecida presenta todavía grandes carencias, como la falta de detalle de las cuentas. Por ejemplo, en el caso de los bienes inmuebles (viviendas y terrenos) no se especifica el número, el tipo de propiedad (rústica, industrial, etc.), la situación o superficie, la fecha de adquisición o el porcentaje de participación en la propiedad del político (¿son propiedades familiares sujetas a régimen de bienes gananciales, propiedades individuales, etc.?). Tampoco concreta el registro cuáles son las propiedades incluidas en "otros bienes", si pertenecen a inmovilizado inmaterial, o al financiero... etc. Parece existir una especie de temor a proporcionar datos económicos que puedan revelar demasiado, un temor que se acrecienta cuanto más elevado es el rango del poder ejecutivo.

Esto se evidencia cuando se comparan estas presentaciones con las de algunas comunidades autónomas de España, un ejemplo de transparencia, y no sólo porque fueron las primeras en sacar a la luz las cuentas de sus altos cargos, sino porque su grado de detalle es muy superior. Cabe destacar el caso de Valencia, cuyos políticos incluyen en sus cuentas la situación, la clave o el valor catastral de los bienes inmuebles, y en algunos casos hasta la dirección concreta de una vivienda o la referencia catastral. Lo mismo ocurre con activo no inmobiliario, donde se diferencia entre bienes y derechos, se detalla el tipo (cuenta bancaria, acciones o un coche), en bastantes casos se especifica el valor en euros y en algunos menos se adjunta el número de cuenta. Del mismo modo, en el caso del pasivo, se describe el tipo de deuda (préstamo, crédito, hipoteca...) y el valor en euros.

También es destacable el caso de Castilla La Mancha, donde casi todos los miembros del Gobierno de la Comunidad presentan sus declaraciones de patrimonio aún siendo únicamente voluntaria en el caso de los diputados.

Pero por encima de las importantes diferencias con las comunidades autónomas, hay algo que muchos medios ya denuncian: el valor de los inmuebles que se está presentando es el catastral y no el de mercado o el escriturado, lo que supone una valoración por debajo de la real. En segundo lugar, los ministros casados en régimen de gananciales no declaran el $100 \%$ del valor de los bienes que comparten con su cónyuge sino el $50 \%$ que les corresponde. 
Además, en cuanto al análisis cuantitativo de datos, está la difícil credibilidad de algunas de las cuentas presentadas, que dejarían en situación de quiebra técnica al grupo de ministros y secretarios cuyo ratio de coeficiente de garantía mostrado anteriormente es inferior a 1.

Respecto a las lagunas legales, a pesar de que la ley 5/ 2006 enumeraba como cargos sujetos a declaración de intereses a "los miembros del Gobierno, los Secretarios de Estado y al resto de los altos cargos de la Administración General y de las entidades del sector público estatal, de derecho público o privado, vinculadas o dependientes de aquélla", (Ley Regulación DE CONFLictos, 2006: art. 14.3) sólo se hacen públicas en el BOE las referidas al presidente y los 42 ministros y secretarios, dejando fuera a todos los demás sujetos sometidos a declaración.

Muchas de las carencias se derivan en su mayor parte de la ambigua redacción de la ley $5 / 2006$, a la que ya se hacía mención en un epígrafe anterior. Es preciso recordar que en dicha ley se establecía una distinción entre los datos existentes en el Registro de Bienes y Derechos Patrimoniales, de carácter reservado, y los de las Declaraciones de bienes y derechos patrimoniales, con carácter público sólo estos últimos.

Esto nos lleva a pensar que los datos ausentes en esta declaración publicada en el BOE, como el número de inmuebles de los ministros o el resto de bienes que forman parte de su patrimonio, sí están recogidos en el Registro de Bienes y Derechos. Prueba de ello son los testimonios obtenidos por el periódico El Mundo (2009), quien declara que "las fuentes consultadas destacaron que todos ellos han tenido que rendir cuentas detalladas de todas sus posesiones al Registro de Bienes y Derechos Patrimoniales, aunque estas declaraciones detalladas no se hayan hecho públicas" (El Mundo, 2009).

Por otro lado, la redacción del artículo 14.4 es también digna de analizar. Allí se indica que "se publicará una declaración comprensiva de la situación patrimonial de estos altos cargos, omitiéndose aquellos datos referentes a su localización y salvaguardando la privacidad y seguridad de sus titulares" (Ley Regulación, 2006: art.14.4). En primer lugar la palabra "comprensiva" ya parece indicar que se está tratando de justificar las posibles carencias bajo la excusa de una delicadeza hacia los miembros del Gobierno. En segundo lugar, se emplea la famosa justificación basada en la salvaguarda de la privacidad para no ofrecer datos detallados cuando, en realidad, una información sin detallar de este estilo no sirve de mucho ya que imposibilita la comprobación de la veracidad de lo declarado.

\section{La tímida reacción de los medios}

Es curioso observar cómo los medios, los que más se pueden beneficiar del aperturismo informativo, se limitaron a recoger las cuentas del presidente y sus 17 ministros, dejando fuera a los 25 secretarios y contribuyendo así a un descarado recorte de la información. Por otro lado, la información convertida en noticia se limitó al tradicional relato asistemático e incompleto sin referencias exhaustivas de cada caso y sólo enfatizando circunstancias dispersas. Por consiguiente, la accesibilidad pública de las declaraciones no se traduce en una revisión global, sistemática y en profundidad me- 
diante el periodismo convencional, que acerque a los ciudadanos un conocimiento exhaustivo y realmente transparente de la cuestión.

Por este motivo, a pesar del gran avance acometido en 2009, sumado al ejemplo de las CCAA, el modelo aún puede perfeccionarse mucho. Entre las mejoras necesarias cabe proponer la unificación de la legislación estatal y autonómica, aumentar el nivel de detalle de las cuentas fiscales y extender esta publicación al conjunto de las comunidades autónomas así como al Congreso (donde las cuentas patrimoniales no son públicas). En general, se trataría de tomar conciencia de la importancia de la fiscalización de los poderes públicos por los ciudadanos, sobre todo por parte de los propios periodistas. Sólo con eso, ya conseguiríamos un modelo más transparente.

Dicho avance hacia la transparencia no puede ser contemplado simplemente como una pretensión de periodistas deseosos de mayores cotas de 'materia prima' con la que incrementar su mercado de noticias sensacionales, sino como una condición imprescindible para transformar un sistema político desde las relaciones políticas entre soberanos y cortesanos, en otro verdaderamente democrático, de relaciones políticas naturales entre representantes y ciudadanos (TENA, 2011). Habida cuenta de que -como señala SALVADOR CODERCH (2010)-, "toda burocracia persigue gestionar autónomamente la información que atesora, auténtica base de su poder", la conversión de los privilegios informativos cortesanos en un igualitario espacio público democrático depende de manera ineludible, como también señala Rodrigo TENA (2011), de la exigencia de una transparente rendición de cuentas a nuestros representantes. Y el periodismo de precisión constituirá, acto seguido, la mejor estrategia de análisis que el perro guardián podrá emplear para fiscalizar esas cuentas, demostrando así que no es un simple can desdentado, limitado todo lo más a ladrar ante los gestos ostentosos del César.

\section{Referencias bibliográficas}

BANISAR, David (2003): Freedom of Information and Access to Government Record Laws around the World. 28 de Septiembre.

BRITISH FREEDOM OF INFORMATION ACT 2000 c. 36. National Archives 30$\mathrm{XI}$.

COALICIÓN PRO ACCESO (2008): "La coalición Pro Acceso reclama para España una ley de acceso a la información pública" en: www.transparencia.org/COALICIÓN PRO ACCESO RECLAMA LEY ACCESO INFORMACIÓN.pdf [fecha de consulta: 01-05-2010].

CONSEJO DE EUROPA (2009): “Council of Europe Convention on Access to Oficial Documents" en: http://conventions.coe.int/Treaty/EN/Treaties/Html/205.htm [fecha de consulta: 15-02-2011]

CONSTITUCIÓN ESPAÑOLA (C.E.) (1978): BOE 29-XII.

DADER, José Luis (2001): "La democracia débil ante el populismo de la privacidad: terror panóptico y secreto administrativo frente al periodismo de rastreo informático en España”, en Anàlisi, Quaderns de Comunicació i Cultura. (Barcelona, Universidad Autónoma, Bellaterra), n² 26: 146-168. 
DADER, José Luis (2009): Curso General de Periodismo de Precisión. Apuntes de Clase. Madrid. Facultad de Ciencias de la Información. Universidad Complutense.

DJANKOV, Simeon et al. (2009): "Disclosure and enforce indices by income groups". Disclosure by politicians, en American Economic Journal en : http:/www.aeaweb.org/articles.php?doi=10.1257/app.2.2.179 [fecha de consulta: 10-12-2010]

EL MUNDO (2009): “Sebastián, segundo ministro más rico, presume de pagar sus trajes", en El Mundo, 15 octubre.

ELECTRONIC FREEDOM OF INFORMATION ACT (EFOIA) (1996): Public Law No. 104-231, 110. Stat. 3048. Estados Unidos.

EUROPA PRESS (2008): "El gobierno no cumplirá su promesa de publicar los bienes del gobierno hasta suprimir el impuesto de patrimonio", en Europa Press, en: http://www.europapress.es/nacional/noticia-gobierno-no-cumplira-promesapublicar-bienes-ministros-suprimir-impuesto-patrimonio-20081119124031.html [fecha de consulta: 10- 04-2010]

EUROPA PRESS (2008): "IU-ICV plantea hoy en el Congreso dar tres meses al Gobierno para regular la publicación de los bienes de ministros", en Europa Press, en: http://www.europapress.es/nacional/noticia-iu-icv-plantea-hoy-congreso-dartres-meses-gobierno-regular-publicacion-bienes-ministros-20081125075523.html [fecha de consulta: 02-05-2010]

FREEDOM OF INFORMATION ACT (FOIA) (1966): Ley de la libertad de Información, Public Law. No. 89-554, 80 Stat. 383. Estados Unidos.

GONICK Larry y SMITH, Woolcott (1999): La estadística en cómic (v.o. 1993). Barcelona, Zendrera Zariquiey.

HALLIN, Dan (ed. 1997): "Comercialidad y profesionalismo en los medios periodísticos estadounidenses", Cuadernos de Información y Comunicación (CIC), $\mathrm{n}^{\circ}$ 3: $123-144$.

LEY 30/1992 DEL RÉGIMEN JURÍDICO DE LAS ADMINISTRACIONES PÚBLICAS Y DEL PROCEDIMIENTO ADMINISTRATIVO COMÚN. BOE 27-XI.

LEY 38/1995 SOBRE LIBERTAD DE ACCESO A MEDIO AMBIENTE. Actualizada por la LEY 27/2006. BOE 19-VII.

LEY 5/2006 DE REGULACIÓN DE CONFLICTOS DE INTERESES DE ALTOS CARGOS. BOE 11-IV.

LEY ORGÁNICA 15/1999 DE PROTECCIÓN DE DATOS DE CARÁCTER PERSONAL (LOPD). BOE 14-XII.

LOI 78-17, (1978): RELATIVE A L'INFORMATIQUE, AUX FICHIERS ET AUX LIBERTES. Modificada por última vez por Loi n²009/526 (2009). Journal Officiel 13-V.

MEYER, Philip (1989): "Precision Journalism and the 1988 US Elections", en International Journal of Public Opinion Research, vol. 1. Oxford University Press, 3. 
MEYER, Philip (1993): Periodismo de precisión. Nuevas fronteras para la investigación periodística. (v.o. 1991). Barcelona. Bosch.

MINISTERIO DE LA PRESIDENCIA DE ESPAÑA (2009): Resolución de 13 de octubre de la Secretaría de Estado para la Función Pública por la que se da cumplimiento a la dispuesto en el artículo 14.4 de la Ley 5/2006, de 10 de abril, de regulación de los conflictos de intereses de los miembros del Gobierno y de los Altos Cargos de la Administración General del Estado. BOE, N 249, de 15 de octubre.

OPEN GOVERMENT ACT (2007): Openness Promotes Effectiveness in our National Government Act, Public Law No. 110-175, 121 Stat. 2524. Estados Unidos.

PORTILLA, Idoia (2004): Estadística descriptiva para comunicadores. Aplicaciones a la publicidad y las relaciones públicas. Pamplona, Eunsa.

RESOLUCIÓN DE LA SECRETARIA DE ESTADO PARA LA FUNCIÓN PÚBLICA (2009): BOE, 15- X.

RODRÍGUEZ, Pepe (2010): "Periodismo y datos publicados en Internet: el concepto de 'fuente accesible al público' y otras restricciones de la Ley de Protección de Datos Personales", Textual \& Visual Media, No 3: 217-238.

SALVADOR CODERCH, Pablo (2010): "Secretos profundos y superficiales", El País, 26 de mayo, p. 31.

SPEIER, Hans (1972): "El desarrollo histórico de la opinión pública”, en STEINBER; Bluem (eds.): Medios de masas y comunicación. México, Roble. Edición original de 1950.

STOCKBURGER, David (1998): "Introductory Statistics: Concepts, Models, and Applications". Missouri State University en: www.psychstat.missouristate.edu/introbook/sbk00.htm [fecha de consulta: 17-02-2011]

SUNSHINE ACT (2006): Public Law. 729, No. 93, § 1. Pennsylvania, Estados Unidos.

TENA, Rodrigo (2011): "Cortesanos y ciudadanos", El Mundo, 15 de febrero.

VAUGHN, G. Robert (2000): "Transparencia. Los mecanismos: Gobierno abierto y rendición de cuentas". Temas de la democracia. La responsabilidad gubernamental. Publicación electrónica del departamento de Estados Unidos en: $\mathrm{http}: / / \mathrm{www}$.usembassy-mexico.gov/bbf/periodicoselectronicos.htm [fecha de consulta: 03-03-2010]

WHITAKER, Reg. (1999): El fin de la privacidad. Cómo la vigilancia total se está convirtiendo en realidad. Barcelona. Paidós. 